\title{
Experimental research on citation tone of Guangling dialect
}

\author{
Hongjie Wang ${ }^{1, a}$ Yonghong $\mathrm{Li}^{1, \mathrm{~b}, \text { * }}$ \\ ${ }^{1}$ Key Laboratory of China's National Linguistic Information Technology(Northwest \\ Minzu University), Ministry of Education, Lanzhou 730030,China \\ a1778157404@qq.com, blyhweiwei@126.com
}

\begin{abstract}
This paper will use the method of experimental to study the tone of Guangling dialect and the normalized, analyzes the types and differentiation of tones in the dialect, summarize the value and range of Guangling dialect tone. Finally we find that there are four tones in Guangling dialect: Yinping(52)、Yangping (41)、 Shang (44) and Qu(413). There is a trend of consolidation between Yinping and Yangping. The objective is to describe the actual situation objectively, for the further study of Guangling dialect to provide a reference.
\end{abstract}

Keywords: Guangling dialect, tone, phonetic experiment

\section{Introduction}

Guangling is located in the northeast of Shanxi Province, the language of Shanxi is mainly about Jin. Guangling dialect is very special. Guangling is located in Shanxi, Datong, its dialect is not belong to Jin but to Laifu dialectal area of Jilu Mandarin. The main features of Jilu Mandarin are mostly have Yinping, Yangping, Shang and Qu four tones, they are divided and merged from ancient four tones.

At present, the research of Guangling dialect is very small, only Mr. Ma Wenzhong did an in-depth study. His book Guangling Dialect analyzed this dialect deeply from three aspects : phonetics, vocabulary and grammar. In the book he summed up that Guangling dialect has 20 initials(including zero initial) and 32 finals. He points out that there are four tones in Guangling dialect: Yinping(53), Yangping(31), Shang(55) and Qu (213). The research is only in theory. These conclusions are get through the traditional method to.In order to compensate for this deficiency, this paper will examine the Guangling dialect tones by the method of experimental phonetics and describe the tones objectively. Aim is to provide reference for further study.

\section{Experimental description}

\subsection{Pronouncing list}

This paper is based on the China Language Work Committee issued the China language resources survey Handbook to determine the experimental pronunciation list ( Table 1). There are four ancient tones and each can be divided voiceless(全清)、 asperational voiceless(次清)、secondary voiced(次浊) and voiced(全浊) four ancient sounds. 
Table 1 Pronunciation List

\begin{tabular}{|c|c|c|c|c|c|}
\hline $\begin{array}{l}\text { Ancient } \\
\text { tone }\end{array}$ & $\begin{array}{c}\text { Ancient } \\
\text { sound }\end{array}$ & words & $\begin{array}{c}\text { Ancient } \\
\text { tone }\end{array}$ & $\begin{array}{c}\text { Ancient } \\
\text { sound }\end{array}$ & words \\
\hline \multirow{4}{*}{ Ping } & Voiceless & 东、该、灯、风 & \multirow{4}{*}{ Qu } & Voiceless & 冻、怪、半、四 \\
\hline & $\begin{array}{l}\text { Asperational } \\
\text { voiceless }\end{array}$ & 通、开、天、春 & & $\begin{array}{l}\text { Asperational } \\
\text { voiceless }\end{array}$ & 痛、快、寸、去 \\
\hline & $\begin{array}{l}\text { Secondary } \\
\text { voiced }\end{array}$ & 门、龙、牛、油 & & $\begin{array}{c}\text { Secondary } \\
\text { voiced }\end{array}$ & 卖、路、硬、乱 \\
\hline & Voiced & 铜、皮、糖、红 & & Voiced & 洞、地、饭、树 \\
\hline \multirow{4}{*}{ Shang } & Voiceless & 懂、古、鬼、九 & \multirow{4}{*}{$\mathrm{Ru}$} & Voiceless & 谷、百、搭、节、急 \\
\hline & $\begin{array}{c}\text { Asperationl } \\
\text { voiceless }\end{array}$ & 统、苦、讨、草 & & $\begin{array}{l}\text { Asperationl } \\
\text { voiceless }\end{array}$ & 哭、拍、塔、切、刻 \\
\hline & $\begin{array}{l}\text { Secondary } \\
\text { voiced }\end{array}$ & 买、老、五、有 & & $\begin{array}{l}\text { Secondary } \\
\text { voiced }\end{array}$ & 六、麦、叶、月 \\
\hline & Voiced & 动、罪、近、后 & & Voiced & 毒、白、盒、罚 \\
\hline
\end{tabular}

\subsection{The informant}

The informant is come from Guangling county. she was born in 1993.Before she went to college in 2012, her language environment is Guangling dialect. She divorced from Guangling dialect is not a long time. During university she often speak Guangling dialect. The recording time is March 5, 2017. recorded sounds in the phonetic laboratory at Northwest Minzu University.

\subsection{Experimental tools and analysis software}

The main tool is the pronunciation table, it is determined according to the 'manual' China language resource survey. Lenovo notebook and headset microphone. Software includes Adobe Audition3.0 and Praat5.0. In addition, there is a standardized script, which is used to measure and extract the fundamental frequency, and finally calculate the five degree.

\subsection{Experimental process}

First of all, recording sounds in the voice laboratory with Adobe Audidtion3.0 recording software. Sampling frequency of $22050 \mathrm{~Hz}$ and single channel recording. The speaker reads each word three times and save each time as a wav format. Then using the Praat5.0.11 speech processing software to extract the fundamental frequency of tones and save the parameters in the computer. For each tone, the Praat and the normalized script program are used to extract the values of 30 fundamental points. Make pitch curves for each tones. At last, we will get the upper limit of the range $(\mathrm{RH})$, the lower limit of the range(RI) and the width of the field(R).

In order to make the data more universal significance, we do further normalization according to the F0 data. Finally converted to the traditional five degree value, make their $\mathrm{T}$ values and make a chart. When the fundamental frequency is normalized, we use the $\mathrm{T}$ algorithm and the formula is:

$\mathrm{T}=[(\operatorname{lgf} 0-\operatorname{lgmin}) /(\lg \max -\lg \min )] * 5$

F0 is the average fundamental frequency of the measured points. The min is the lower limit of the fundamental frequency. The max is the maximum value of the upper limit of the modulation domain. That is the max and min take the maximum and the minimum values of all the points in the T. The value of $\mathrm{T}$ calculated by this method is between zero and five. The correspondence between the $\mathrm{T}$ value and the five degree 
value is: $T$ value in the range of zero and one, the corresponding value of five degrees is one. The corresponding value of $\mathrm{T}$ value between one and two, which is two. The $\mathrm{T}$ value is between two and three, the corresponding value of five degrees is three. The corresponding value of $\mathrm{T}$ value between three and four, which is four. The corresponding value of $\mathrm{T}$ value between four and five, which is five.

\section{Results and discussion}

\subsection{Fundamental frequency and range}

The fundamental frequency of the recorded sound is extracted and processed, calculate and analyzed the initial mean value( $\mathrm{Hz})$, middle mean value $(\mathrm{Hz})$, final mean value $(\mathrm{Hz})$, maximum value $(\mathrm{Hz})$ and minimum value $(\mathrm{Hz})$ of each set of data. The following is a specific analysis of the four tones.

Table 2 Guangling tone pitch parameters $(\mathrm{Hz})$

\begin{tabular}{|c|c|c|c|c|c|c|}
\hline \multicolumn{2}{|r|}{ Tones } & $\begin{array}{c}\text { Initial } \\
\text { mean value }\end{array}$ & $\begin{array}{c}\text { Middle } \\
\text { mean value }\end{array}$ & $\begin{array}{c}\text { Final } \\
\text { mean value }\end{array}$ & $\begin{array}{l}\text { Maximum } \\
\text { value }\end{array}$ & $\begin{array}{l}\text { Minimum } \\
\text { value }\end{array}$ \\
\hline \multirow{4}{*}{ Ping } & Voiceless & 259.8 & 241 & 198.8 & 274.7 & 192.1 \\
\hline & Asperational voiceless & 262.4 & 239.4 & 198.4 & 273.0 & 189.5 \\
\hline & Secondary voiced & 239.8 & 220.5 & 189.1 & 245.9 & 180.1 \\
\hline & Voiced & 254.3 & 210.8 & 191.8 & 255.6 & 179.0 \\
\hline \multirow{4}{*}{ Shang } & Voiceless & 212.5 & 207.0 & 209.8 & 210.0 & 205.4 \\
\hline & Asperational voiceless & 208.9 & 203.8 & 210.8 & 219.3 & 200.6 \\
\hline & Secondary voiced & 202.3 & 207.8 & 203.3 & 218.5 & 189.4 \\
\hline & Voiced & 210.5 & 177.0 & 207.2 & 224.2 & 170.4 \\
\hline \multirow{4}{*}{$\mathrm{Qu}$} & Voiceless & 228.7 & 183.4 & 209.5 & 244.6 & 177.5 \\
\hline & Asperational voiceless & 235.2 & 180.5 & 208.7 & 245.1 & 198.1 \\
\hline & Secondary voiced & 234.9 & 180.9 & 202.2 & 251.5 & 171.7 \\
\hline & Voiced & 210.6 & 176.6 & 208.8 & 223.6 & 173.8 \\
\hline \multirow{4}{*}{$\mathrm{Ru}$} & Voiceless & 223.4 & 208.7 & 199.1 & 240.3 & 185.6 \\
\hline & Asperational voiceless & 245.2 & 229.2 & 205.2 & 276.8 & 183.4 \\
\hline & Secondary voiced & 219.6 & 191.8 & 210.3 & 230.1 & 160.8 \\
\hline & Voiced & 240.2 & 202.4 & 187.1 & 265.0 & 180.6 \\
\hline
\end{tabular}

In phonology, Ping tone is divided into Yinping and Yangping. In Guangling dialect, Yinping and Yangping are both falling tones. There are differences between these two tones in the upper limit of the range,the lower limit of the range and the width of the field, but those difference are not obvious. They have a tendency to merge together.

About Shang, the upper limit of the range is $224.2 \mathrm{~Hz}$, the lower limit of the range is $170.4 \mathrm{~Hz}$, the width is $53.8 \mathrm{~Hz}$. In this tone, the fundamental frequency of voiceless 、 asperational voiceless and secondary voiced are coincident, the voiced is different with them.

The fundamental frequency of $\mathrm{Qu}$ is decreased first and then increased. Its upper limit and the lower limit of the range are $251.5 \mathrm{~Hz}$ and $171.7 \mathrm{~Hz}$, and the width is $79.8 \mathrm{~Hz}$. So we think it is a tortuous tone. The frequency range of $\mathrm{Qu}$ and change trend are similar to the voiced in Shang, so they can be combined together.

$\mathrm{Ru}$ is the most complicated in these four tones. In Guangling dialect, voiceless and asperational in $\mathrm{Ru}$ are both falling tones. The upper limit and the lower limit of the range are $276.8 \mathrm{~Hz}$ and $183.4 \mathrm{~Hz}$, and the width is $93.4 \mathrm{~Hz}$. Its fundamental trend as 
well as the domain wide are same with Yinping, so it can be merged into Yinping. About secondary voiced initials, it can be seen as a tortuous tone through the change of fundamental frequency. After comparison we find that its frequency range and change trend are similar to $\mathrm{Qu}$, so we can merge them together. The voiced tone is a falling tone. Its upper and lower limits of range are $265 \mathrm{~Hz}$ and $180.6 \mathrm{~Hz}$ and the span of the range is $84.4 \mathrm{~Hz}$. So we merge it with Yangping.

To sum up, great changes have taken place in these four tones of Guangling dialect. The tone of Ping has divided into two parts, they are Yinping and Yangping. With the change of sound quality they have a tendency to merge together. About Shang, voiceless, asperational voiceless and secondary voiced are still Shang, only voiced are merged into $\mathrm{Qu}$. The situation of $\mathrm{Ru}$ is more complex. The voiceless and asperational voiceless are classified into Yinping. The muddy are classified into $\mathrm{Qu}$ and the voiced are classified into Yangping. It can be seen that in the Guangling dialect Ru tone has disappeared.

\subsection{Five degree value}

According to $\mathrm{T}$ algorithm, in this experiment, we extract the 30 fundamental average values of each tone into F0. Finally we obtained the T curves of these four tones. The abscissa is the tone point, the ordinate is $\mathrm{T}$ values.

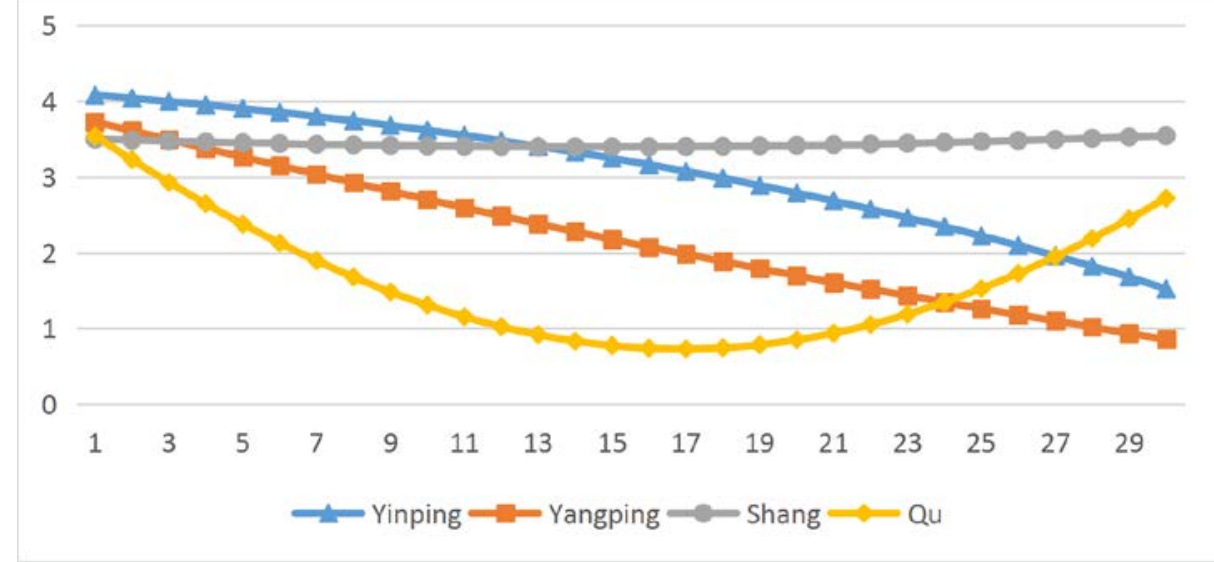

Fig. $1 \mathrm{~T}$ curves of four tones

From the above figure, there are four tones in Guangling dialect: Yingping (52)、 Yangping(41)、Shang(44)、Qu(413). The result is quite different from what $\mathrm{Mr} \mathrm{Ma}$ Wenzhong has concluded. The experiment shows that Yinping and Yangping are both falling tones. Shang is a level tone. Qu is a tortuous tone.

Finally, figure 2 is a description of the differentiating and merging of all tones. 


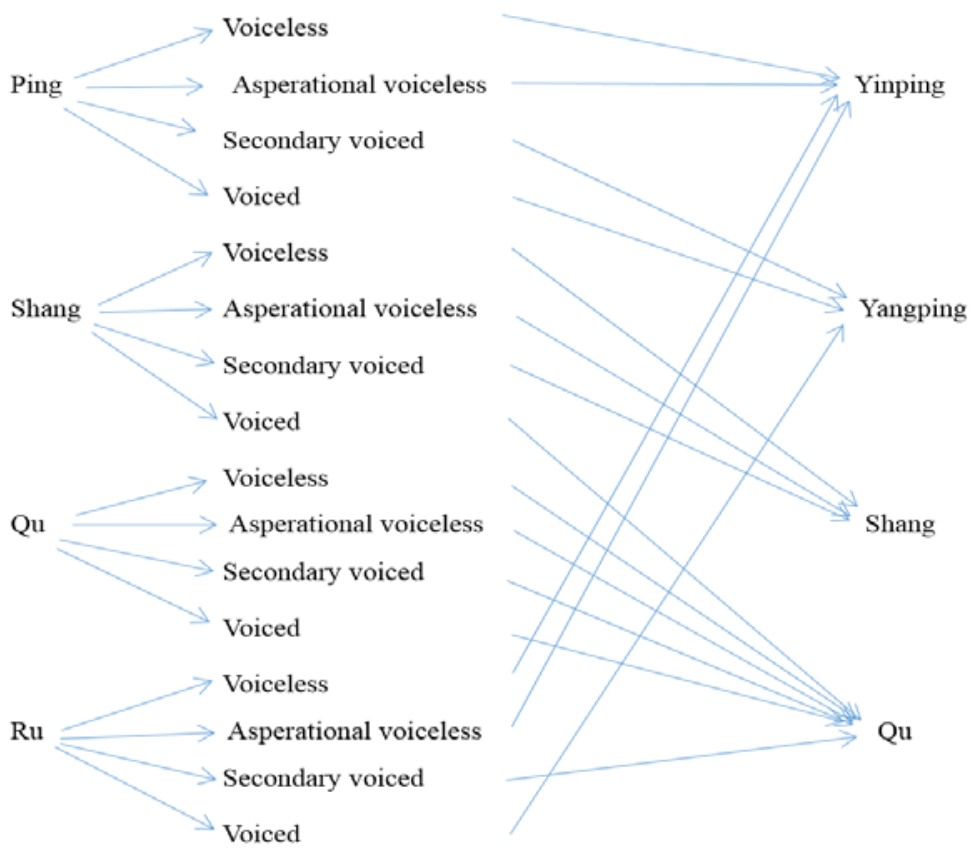

Fig.2 The differentiating and merging of all tones

\section{Conclusions}

By acoustic analysis, this paper sum up the Guangling dialect's tones system and pitch range, the results are slightly different from previous studies. The experimental results are as follows: There are Yinping、Yangping、Shang、Qu four tones in Guangling dialect. Yinping is a falling tone, its value is 52. Yangping is also a falling tone, its value is 41. Yinping and Yangping had the trend toward merge. Shang is a level tone, its value is 44 . Qu is a tortuous tone, its value is 413 .

\section{Acknowledgements}

This work was financially supported by the Central University Youth Innovation Team Project-Speech multimodal (31920160002) and Central University Innovation Project- Gansu county dialect speech acoustics research(Yxm2017107).

\section{References}

[1]Wang Linhui ,The type of tone in Shanxi dialect (Draft),Language research, 2003. [2]Xian Wenting, Tang Qiyuan, Experimental study on the tone of Yangjiang dialect, Journal of Liuzhou Teachers College, 2014.

[3]Ma Wenzhong, Guangling dialect, Shanxi University Press, 1994.

[4]Wu Zongji, Lin Maocan, Experimental phonetics overview, Beijing, Higher Education Press, 1989.

[5]Shi Feng,Tone analysis of the two word group in Tianjin dialect, language research, 1986.

[6]Zhao Zhiguo,Analysis of tone of atypical Zichuan dialect, Journal of Lianyungang Teacher's College, 2011. 